\title{
Optimal Tax Policy Based on Endogenous Growth Model of Economy
}

\author{
Jin Ying ${ }^{a}$, Cai Defa ${ }^{b}$ \\ Finance and Public Management College, Harbin University of Commerce, P.R. China, 150028 \\ ahsdjiny@163.com, babcd04754@126.com
}

Keywords: Low-Carbon Economy (LCE); Endogenous Growth model; The optimal tax

\begin{abstract}
In this paper, we use the endogenous growth model to build production function and utility function, By solving it, we concludes that when the government stable tax policy has been implemented, low carbon consumers have a unique optimal capital stock path, along this path it can promote the steady and optimal economic growth, we also discuss the tax policy influence on low carbon economic growth under the condition of market equilibrium, and get know how to adjust the tax rate to achieve the optimal low-carbon economic growth.
\end{abstract}

\section{Introduction}

The essence of low-carbon economy is the high energy efficiency and clean energy structure, the core is a fundamental change of energy technology innovation, system innovation and the concept of human survival and development. Based on the theory of low carbon economy foundation, combined the endogenous growth model, In the market equilibrium condition to discuss the effect of tax policy on economic growth and how to adjust the tax policy can achieve the optimal growth of low-carbon economy.

\section{The Construction of the Model}

\subsection{Production function}

Assuming that under the condition of market equilibrium, the representative of low carbon consumers, producers and government constitute the three themes of low carbon economy.

\subsubsection{Low carbon consumers behavior}

In order to meet the maximization of consumer and capital utility, low carbon consumers optimally choose the path of low carbon consumption and capital with the constraint of government budget, so we can write low carbon consumer supremum function as follows: $\sup =\int_{0}^{\infty} u[C(t), G(t)] e^{-\mu t} d t$

Among them, $\mathrm{C}(\mathrm{t})$ is expressed as low carbon consumer in the $\mathrm{t}$ phase of the consumption path; $\mathrm{G}(\mathrm{t})$ is expressed as government expenditure in the $\mathrm{t}$ phase, in government spending, low carbon consumers gain the increasing but diminishing marginal utility. $\mathrm{u}$ is expressed as discount factor, on behalf of the consumers time preference rate, the greater the value of u means consumers think the current low carbon consumption utility is greater than the future consumer utility. Low carbon consumers will have to pay taxes to the government besides gain some income from capital investment which is put into production, so we can express budget constraint as follows: $\frac{d K}{d t}=(1-\tau) s K-C$

Among them, $\mathrm{k}$ is expressed as the capital stock; $\tau$ is expressed as the government tax rate; $\mathrm{s}$ is expressed as the marginal productivity of capital.

\subsubsection{Low carbon producers behavior.}

In pursuit of maximization of excess profit, low carbon resource producers choose the optimal production path under the environmental constraint conditions, so we can write objective function as 
follows: $\max [F(K, G)-s K]$

After inserting the low carbon technical level A into production procedure, we can write production function as follows:

$$
Y=F(K, G)=A K^{\alpha} G^{1-\alpha}
$$

Assuming that assumption market is in fully competitive equilibrium, the excess profit is zero, so $\mathrm{sK}=\mathrm{F}(\mathrm{K}, \mathrm{G})$. Bringing low carbon resources producer behavior into low carbon consumers budget equation can be concluded as follows: $\sup =\int_{0}^{\infty} u[C(t), G(t)] e^{-\mu t} d t, \frac{d \mathrm{~K}}{d t}=(1-\tau) s \mathrm{~K}-\mathrm{C}$

\subsubsection{Government behavior}

Supposing that the government only uses taxes to meet the expenses in the budget balance, namely:

$$
G=\tau F(K, G)
$$

$\mathrm{R}(\mathrm{t})$ is expressed as the growth rate of capital stock, then $\frac{d K(t)}{d t}=R(t) K(t)$,so constraints turn to be as follows:

$$
R K=F(K, S)-G-C
$$

The formula considers low carbon consumer budget constraints, low carbon producer of optimal pursuit and equilibrium conditions concluded by government constraints equation. By the formula (1) and (3), it can be seen that the consumption level $C$ and government spending $G$ can be the variables in the function of capital stock $\mathrm{K}$, the growth rate $\mathrm{R}$ and tax rate $\tau$ function, namely $\mathrm{u}[\mathrm{C}, \mathrm{G}]$ can be viewed as a function defined on the ${ }^{[K, R, \tau]}$. Therefore, the introduction of government spending endogenous economic growth model can be written as:

$$
\sup \int_{0}^{\infty} u[K(t), R(t), \tau(t)] e^{-\mu t} d t
$$

Among them, $\mathrm{K}(\mathrm{t})$ is expressed as state variables, $\mathrm{R}(\mathrm{t})$ is expressed as control variables .Consumption growth rate is equal to the growth rate of output in the model, at the same time is equal to the growth rate of capital accumulation, they are referred as economic growth. Tax rate influences capital growth rate , then affects economic growth.

\subsection{The utility function}

Assuming that $\mu(d t)=\exp (-\mu t)=e^{-\mu t}$, formula (4) can be written as below:

$V \tau\left(K_{\mathrm{o}}\right)=\sup \int_{0}^{\infty} u[K(t), R(t), \tau(t), \mu(d t)]$

Among them, $K_{0}=K(0)$. Assuming that $\mathrm{X}$ and $\mathrm{V}$ are the closed convex set in $R^{n}, \mathrm{D}=\mathrm{X} \times \mathrm{V}$. Because government's tax policy of low carbon influences consumer utility, when the government defines tax-collection rate, we always assume that the utility function satisfy the continuity characteristic.

\section{The solution of the model}

\subsection{The relevant definitions}

A path is called $K(t)$ is feasible, if there is $K(t) \in X$ for all $t$, Assuming that $\bar{R}(t)$ is 
$\bar{K}(t)$ corresponding growth, then $\bar{K}(t)$ is called the optimal path. If for all feasible path from $\bar{K}(0), K(t)$ all satisfies $\int_{0}^{\infty} u[\bar{K}(t), \mu(t), \bar{R}(t)] \mu(d t) \geq \int_{0}^{\infty} u[K(t), R(t), \tau(t)] \mu(d t)$; If in addition to the one above, $\bar{R}(t)$ also meets $\bar{R}=\bar{R}(t)$, then $\bar{K}(t)$ is referred as the steady optimal growth path. $\bar{R}$ is accordingly known as the optimal growth rate.

\subsection{Related theorem and solution.}

(1) Assuming that tax path of is constant, namely $\tau(\mathrm{t}) \equiv \tau$, the definite tax path ${ }^{\tau(t)}$ makes $\tau(t) \rightarrow \tau$, then there must be unique steady optimal growth path, the growth rate $R(t) \rightarrow R_{\tau}$, By the definition of the optimal path:

$$
\begin{aligned}
& \phi\left[K_{\tau}, \bar{R}(t), \tau(t)\right] \geq \phi\left[K_{\tau}, R_{\tau}, \tau(t)\right] \\
& \phi\left[K_{\tau}, R_{\tau}, \tau(t)\right] \geq \phi\left[K_{\tau}, \bar{R}(t), \tau\right]
\end{aligned}
$$

Take the limit of formula (6), (7) on t for both sides, it is concluded that:

$$
\begin{gathered}
\phi\left[K_{\tau}, \lim _{t \rightarrow \infty} \bar{R}(t), \tau\right] \geq \phi\left[K_{\tau}, R_{\tau}, \tau\right] \\
\phi\left[K_{\tau}, R_{\tau}, \tau\right] \geq \phi\left[k_{\tau}, \varliminf_{t \rightarrow \infty} \bar{R}(t), \tau\right]
\end{gathered}
$$

By the formula (8) and (9), it is concluded that: $\phi\left[K_{\tau}, \lim _{t \rightarrow \infty} \bar{R}(t), \tau\right] \geq \phi\left[K_{\tau}, \lim _{t \rightarrow \infty} \bar{R}(t), \tau\right]$

In the same way, respectively take inferior limit ot $\mathrm{t}$ on both sides, it is concluded that: $\phi\left[K_{\tau}, \lim _{t \rightarrow \infty} \bar{R}(t), \tau\right] \leq \phi\left[K_{\tau}, \lim _{t \rightarrow \infty} \bar{R}(t), \tau\right]$

So $\phi\left[K_{\tau}, \lim _{t \rightarrow \infty}^{-} \bar{R}(t), \tau\right]=\phi\left[K_{\tau}, \lim _{t \rightarrow \infty} \bar{R}(t), \tau\right]$. By the uniqueness of the optimal smooth path, we can conclude that $\varlimsup_{x \rightarrow \infty} \bar{R}(t)=\varliminf_{t \rightarrow \infty} \bar{R}(t)=R_{\tau}$. so $\lim _{t \rightarrow \infty} \bar{R}(t)=R_{\tau}$, that is in constant function $\bar{R}^{(t)} \rightarrow t^{\tau}$. To sum up, $\bar{Y}(t)$ is the one and only optimal path to meet $\bar{R}(t) \rightarrow R_{\tau}$.

(2) Supposing $\mathrm{Y}(\mathrm{t})$ randomly is a feasible path, and it starts from $k_{0}$ and growth rate is $R(t)$,Assuming that there is a optimal path, by the definition of optimality, we know $\Phi\left(K_{0}, R, \tau\right) \leq R$,supposing that $\Phi\left(K_{0}, R, \tau\right)<R$,Because $\Phi$ is continuous in $\mathrm{D}$, so there is $\left(K_{1}, R_{1}\right) \in D$ :

$$
\Phi\left(K_{0}, R, \tau\right) \leq \Phi\left(K_{1}, R_{1}, \tau\right)<R
$$

On D area, the maximum number of $\Phi\left(K_{\tau}, R_{\tau}, \tau\right)$ is, therefore

$$
\Phi\left(K_{\tau}, R_{\tau}, \tau\right) \geq \Phi\left(K_{1}, R_{1}, \tau\right)
$$

By the formula (8) and (9), it is concluded that:

$$
\Phi\left(K_{\tau}, R_{\tau}, \tau\right) \geq \Phi\left(K_{0}, R, \tau\right) \text {, namly } \int_{0}^{\infty} u\left[Y_{\tau}(t), R_{\tau}, \tau\right] \mu(d t) \geq \int_{0}^{\infty} u[Y(t), R(t), \tau] \mu(d t) \text {. }
$$

On account of arbitrariness of $\mathrm{Y}(\mathrm{t}), Y_{\tau}(t)=K_{\tau} e^{R_{\tau} t}$ is the smooth and optimal growth path.

(3) Under the circumstance of random evaluation: $\tau \in[0,1]$, assuming that the sequence

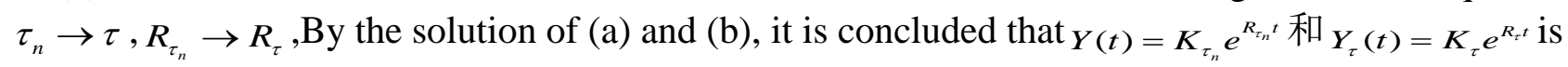
the optimal path for $\tau_{n}\left(\left(k_{\tau_{n}}, r_{\tau_{n}}\right) \in D\right)$ and ${ }^{\tau}\left(\left(k_{\tau}, r_{\tau}\right) \in D\right) \cdot K_{\tau}, R_{\tau}$ is continuous. Continuous function 
exists maximum in a bounded closed set, so there must be $\bar{\tau} \in[0,1]$, for all $\tau \in[0,1], R_{\bar{\tau}} \geq R_{\tau}$ is always reasonable.

Assuming that $\tau_{0} \in[0,1]$ makes $\Phi\left(K_{\tau_{0}}, R_{\tau_{0}}, \tau_{0}\right)>\Phi\left(K_{\bar{\tau}}, R_{\bar{\tau}}, \bar{\tau}\right), R_{\tau_{0}}>R_{\bar{\tau}}$ correct. According to the nature of the concave function, If $0<\tau_{1}<\tau_{2}<\bar{\tau}$, then $\Phi\left(K_{\tau_{1}}, R_{\tau_{1}}, \tau_{1}\right)<\Phi\left(K_{\tau_{2}}, R_{\tau_{2}}, \tau_{2}\right)$, so $R_{\tau_{1}}<R_{\tau_{2}}$, Therefore $\mathrm{R}$ is continuously increasing between 0 and $\bar{\tau}$. For the same reason, $R_{\tau}$ is continuously decreasing between 0 and $\bar{\tau}$ under the condition of $\bar{\tau} \leq \tau_{1}<\tau_{2}<1$.

Conclusion: Assuming that $\mathrm{t}$ is the tax rate that has led to stable and optimal economic growth, When the tax rate is lower than $\bar{\tau}, \mathrm{r}_{\tau}$ is positively correlative to $\tau$, increasing tax is helpful for improving economic growth.

\section{Conclusion}

We can use the endogenous growth model to build production function and utility function, by solving the functions, we can draw the conclusion that: for one ting when the government implements stable tax policy, low carbon consumer has a unique optimal capital stock path that can sustain economic smooth and optimal growth; for another, when the government's tax path is constant, not only can the utility level of the whole society achieve optimal evaluation, but also the growth rate of low carbon economy can reach the maximum point at the same time. when the tax rate is lower than the optimal growth tax rate, increasing taxes can improve low carbon economic growth rate; when the tax rate is higher than the optimal growth tax rate, decreasing taxes can improve low carbon economic growth rate. Therefore, In terms of the tax policy, when the government implements stable tax policy, low carbon consumers have a unique optimal capital stock path that can sustain economic smooth and optimal growth: When the government's tax path is constant, low carbon economy growth rate can reach its maximum evaluation.

Surely, in this paper, the conclusion can provide basic theory basis for management decisions but the lack of data analyzing influences the empirical results. we can improve the conclusion from two aspects in specific: One of them is how to apply the model to the practice, then quantitatively provides the optimal tax policies for the government; The second thing is how to reduce the gap between the model and situation described, in order to make the model closer to reality.

\section{Acknowledgements}

Foundation Project: The national social science fund project(17BJY177); The project for philosophy and social science research base of Heilongjiang Province(16JYD19).

\section{References}

[1] Li Sun. Development and evolution of Endogenous Growth theory [J].Modern economy information, 2012(10):272

[2] Yu Han. Tax system design that boosts Circular Economy development. [J].Tax Research, 2017(3):7-11

[3] DTI, Energy Whitepaper. Our Energy Future-Create a Low-Carbon Economy [J]. London, T SO, 2013, 2-3

[4] S.Chen and M.Zhao. Optimal Generator Portfolio in Day-Ahead Market under Uncertain Carbon Tax Policy [J] .American Journal of Operations Research.2011 (2):56-57

[5] A.Omer. Opportunities for Sustainable Low Carbon Energy Research Development and Applications [J].Low Carbon Economy, 2011(12), 173-191

[6] K.Y.Matsuoka. Developing a Long-Term Local Society Design Methodology towards a 
Low-Carbon Economy: An application to Shiga Prefecture in Japan [J].Energy Policy.2017 (4):44-45

Jin ying (1972-).Woman,lecturer of Finance and Public Management Institute;Cai Defa(1966-):professor,Ph.D,Research Direction:Taxation Theory and Regulation Design. 